\title{
INVESTIGATION THE EFFECT OF RESTORATIONS FABRICATED WITH CAD/CAM TECHNOLOGY, THE HEAT-PRESS TECHNIQUE, AND TYPE OF RESIN CEMENT ON MARGINAL AND INTERNAL ADAPTATION OF ALL CERAMIC CROWNS
}

\author{
Raafat Tammam*
}

\begin{abstract}
Statement of the problem; the use of pressable and CAD/CAM ceramics have been lately frequently used in fixed prosthodontics. However, information about their marginal fit and internal adaptation are is little.

Purpose: Marginal adaptation and internal adaptation are an important factor affecting the longevity of all ceramic restorations, so the purpose of the study was to evaluate the effect of restorations fabricated with $\mathrm{CAD} / \mathrm{CAM}$ technology, the heat-press technique ceramic and luting agent on the Marginal Fit and Internal Adaptation of all Ceramic crowns.
\end{abstract}

Materials \& methods: A total of 20 mandibular Second premolars teeth were used in this study and divided into two groups according to technique of fabrication of ceramic crowns as follow: Machinable ceramics (M). IPS E-max CAD blocks have used for fabrication of ceramic crowns. ( $n=10)$, Pressable ceramics (P). IPS E-max press ingots have used for fabrication of ceramic crowns. $(n=10)$.Each group is divided into two subgroups according to the type of resin cement used as follow: Group T: Ceramic crowns are cemented with total etch Cement-it resin cement $(n=5)$. Group S: Ceramic crowns are cemented with Rely-x self-adhesive resin cement $(n=5)$. A silicone replica was obtained to measure marginal and internal adaptation of each all-ceramic crown before luting, and they were sectioned vertically in mesiodistal direction. Marginal and internal adaptations were measured using computerized light microscope at $100 \times$ magnification. Data were presented as mean and standard deviation (SD) values. Regression model with repeated measures Analysis of Variance two ways (ANOVA) was used in testing significance for the effect of ceramic type and cement type.

Results: related to marginal gap, it was found that press group recorded statistically significant $(\mathrm{P}<0.05)$ higher vertical marginal gap mean value $(55.07 \pm 1.1 \mu \mathrm{m})$ than CAD group $(49.99 \pm 5.57$ $\mu \mathrm{m})$ as indicated by two way ANOVA followed by pair-wise Tukey's post-hoc tests. it was found that vertical marginal gap mean value of self-adhesive cement was statistically non-significant

* Lecturer of fixed prosthodontics, Faculty of Dental Medicine, Assiut University, Egypt, 
$(\mathrm{P}>0.05)$ higher $(54.77 \pm 0.8 \mu \mathrm{m})$ than total etch cement $(50.3 \pm 5.88 \mu \mathrm{m})$.while related to internal adaptation, totally it was found that $\mathrm{CAD}$ group recorded statistically significant $(\mathrm{P}<0.05)$ higher internal gap mean value $(87.45 \pm 15.4 \mu \mathrm{m})$ than press group $(36.64 \pm 5.15 \mu \mathrm{m})$ and it was found that internal gap mean value of total etch cement was statistically significant $(\mathrm{P}<0.05)$ higher $(67.24 \pm$ $11.14 \mu \mathrm{m})$ than self-adhesive cement $(56.85 \pm 9.4 \mu \mathrm{m})$.

Conclusion: Within the limitation of this study, The CAD group recorded statistically significant high vertical marginal fit than press group. The cement type has no effect on the marginal fit. The press group recorded statistically significant high internal fit than CAD group.

Keywords; All-ceramic; marginal adaptation; internal adaptation; CAD/CAM; heat-pressed.

\section{INTRODUCTION}

The final aim of restorative dentistry is to fabricate restorations which are indistinguishable from natural teeth and ceramics are the material of choice for aesthetic restorations because of their excellent translucency, improved fluorescence and great contribution of color from the underlying tooth structure. Not only esthetic but strength and accuracy of fit are also required in an all-ceramic restoration. ${ }^{(1)}$

All-ceramic crowns have become more popular as a result of increasing demand for esthetic corrections.2,3 All-ceramic crowns can be fabricated through computer aided design/computer aided manufacturing (CAD/CAM) or can be heatpressed (HP) ${ }^{2,4}$ The HP technique is based on the lost-wax principle.

Prefabricated ceramic ingots are heated and then pressed into the lost-wax form of a crown coping. Dental CAD/CAM systems such as CEREC (Sirona Dental, Charlotte, NC, USA) use a scanning and milling process to fabricate all-ceramic copings from prefabricated ceramic blocks.5-7 Today it is accepted that all-ceramic crowns should be luted using adhesive luting techniques. ${ }^{8,9}$

Lithium disilicate ceramic restorations (IPS e.max) became commercially available in 2006 , and may be fabricated with a heat-pressed or computeraided design and computer-aided manufacturing (CAD/CAM) fabrication process. Lithium disilicate was initially available as a substructure or core material characterized by better translucency than other high strength ceramic core materials. The favorable translucency and shade variety of lithium disilicate makes possible anatomically contoured monolithic restorations; extrinsic characterization of the monolithic definitive restoration can be applied where needed to improve esthetics. ${ }^{(10-12)}$

Nano-fluorapatite ceramic (IPS e.max Ceram) can be layered onto a lithium disilicate substructure at the incisal, occlusal, or facial areas to improve the optical properties and to customize the esthetic and anatomic contours. ${ }^{(13,14)}$

Computer-aided design/computer-aided manufacturing (CAD/CAM) has been used in dentistry since its development by Duret in France in the 1970 (System Duret CAD/CAM). ${ }^{(48)}$ Among the available (CAD/CAM) systems, the CEREC (CERamic REConstruction) system is one of the most commonly used, as it was the first to be commercially available. This system uses prefabricated high-quality ceramic blocks, resulting in biocompatible, esthetic, and durable restorations. ${ }^{(15,16)}$

Resin luting systems were recommended for the cementation of all-ceramic systems showed significantly stronger all-ceramic crowns are achievable by luting with adhesive resin cements. New type of luting material, called self-adhesive resin cement, that does not require any pretreatment of the tooth surface has been developed. This 
material combines the favorable properties of conventional (zinc phosphate, glass ionomer, and polycarboxylate) and resin cements

A new generation cement system known as self-adhesive resin cement have been developed to eliminate pre-treatment steps such as etching, priming and bonding when compared to multi-step composite cements. Post-operative sensitivity has also been reported as a possible consequence of inadequate polymerization of the resin cement. ${ }^{(17-28)}$ The use of dual-curing resin cements intends to combine chemical and light-polymerization and at the same time allowing polymerization to take place in deeper areas of the tooth cavity applying shorter light irradiation time. ${ }^{(29-39)}$

External marginal adaptation of the crown is defined as the vertical distance between the finish line of the prepared tooth and the margins of the fabricated crowns. ${ }^{(40)}$

In study to evaluate the marginal adaptation and internal fit according to the type of e.max fabrication technique. The adaptation of the restoration was evaluated by means of the silicone replica technique. The lowest marginal discrepancy was measured between the preparation margin on the enamel and the IPS e.max press specimens, the highest discrepancy was observed on the occlusal surface of the IPS e.max CAD specimens. Both systems demonstrated acceptable marginal discrepancies in vitro.IPS e.max press shows higher internal adaptation than IPS e.max CAD. ${ }^{(41)}$

Another a study made in 2014 to evaluate marginal and internal adaptation of ceramic crown restorations fabricated with CAD/CAM technology and the heat-press technique. No significant differences among the CAD/CAM groups were observed for absolute marginal discrepancy. The heat-press group had significantly different values than those of the CAD/CAM groups. The heat-press group yielded the best marginal and internal crown adaptation results. ${ }^{(42)}$
Regard to clinical trial to compare marginal and internal adaptation of two all-ceramic crowns fabricated with $\mathrm{CAD} / \mathrm{CAM}$ and $\mathrm{HP}$ techniques before luting and also to evaluate the clinical outcomes including presence of fractures, sensitivity, and secondary caries at crown margin, marginal discoloration at baseline and at 6, 12, and 24 months after luting. They found that there were no statistically significant differences between $\mathrm{CAD} / \mathrm{CAM}$ and HP all-ceramic anterior single crowns for both marginal and internal adaptation, and a satisfactory clinical performance was observed during a 2-year period. ${ }^{(43)}$

\section{MATERIALS AND METHODS}

\section{TEETH SELECTION}

Twenty human mandibular Second premolars recently extracted and collected from Orthodontic Departments. Teeth were free from caries, micro fractures, or abrasion cavities and had not been previously endodontically treated were selected with approximate similarity in size and shape. The selected teeth had a mesiodistal dimensions of $5 \pm 0.5 \mathrm{~mm}$ and buccopalatal dimensions of $7 \pm 0.5 \mathrm{~mm}$, this was done using digital metal gauge (caliber Pachymeter, Electronic Digital Instrument; China).

Teeth were ultrasonic cleaned to remove any deposits. This was done under copious water coolant to avoid formation of any micro cracks and then stored in 5\% saline solution. All teeth were placed in $2.5 \%$ sodium hypochlorite $(\mathrm{NaOCl})$ for 10 minutes for surface disinfection.

Each tooth was individually mounted in type three hard dental stone, vertically along its long axis of coronal portion. Readymade molds with even size were chosen to fabricate the stone blocks. Each mold has a cylindrical cavity of $7 \mathrm{~cm}$ internal diameter and $5 \mathrm{~cm}$ depth.

A paralleling device (Milling surveyor Paraskop®M, Bego, Bremer, Germany) was used to mount each tooth and to ensure the centralization and alignment of the tooth to the mold (Figure 1). 


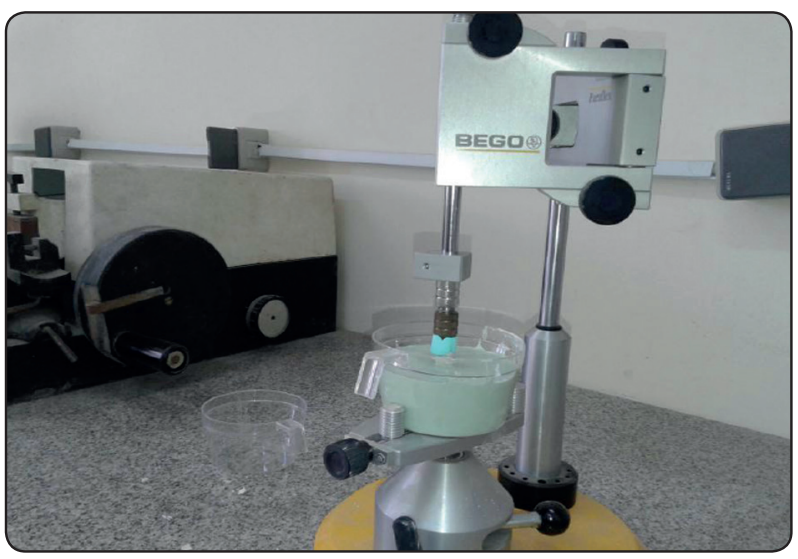

Fig. (1): Milling surveyor used to mount the tooth in the mold

\section{Sample grouping}

A total of 20 mandibular Second premolars teeth were used in this study and divided into two groups according to technique of fabrication of ceramic crowns as follow:

- Machinable ceramics(M). IPS E-max CAD blocks have used for fabrication of ceramic crowns. $(\mathbf{n}=\mathbf{1 0})$

- Pressable ceramics (P). IPS E-max press ingots have used for fabrication of ceramic crowns. $(\mathrm{n}=10)$

Each group is divided into two subgroups according to the type of resin cement used as follow:

- Group T: Ceramic crowns are cemented with total etch Cement-it resin cement $(\mathbf{n}=\mathbf{5})$.

- Group S: Ceramic crowns are cemented with Rely-x self-adhesive resin cement $(\mathbf{n}=\mathbf{5})$.

\section{Teeth preparation}

A mandibular second premolars was prepared for placement of all-ceramic crowns using a parallelometer and diamond stones to ensure accurate replication of the preparation parameters and 20 diamond stones are used for preparation of 20 teeth (Figure 2).

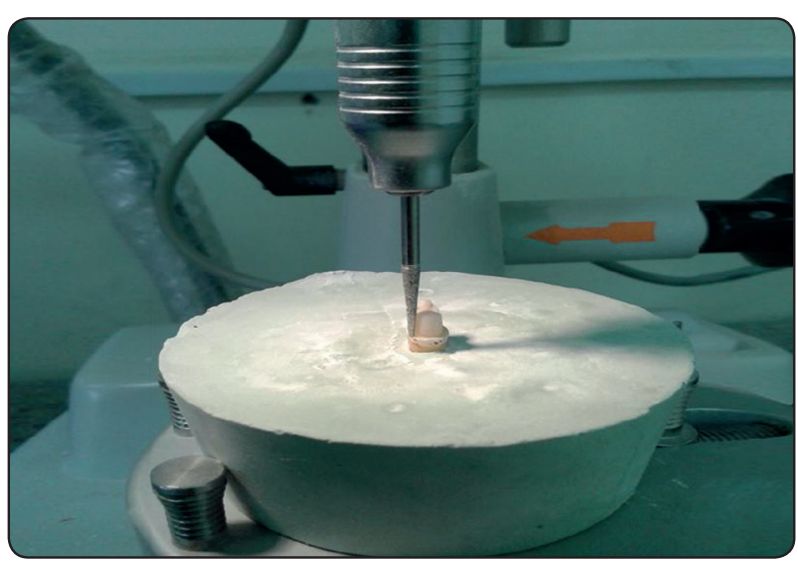

Fig. (2) Milling surveyor used in tooth preparation

The preparation design included a $1.0-\mathrm{mm}$ wide shoulder around the entire circumference, an occlusogingival height of $3 \mathrm{~mm}$, and a $8^{\circ}$ convergence angle. An occlusal reduction of $1.5 \mathrm{~mm}$ was prepared in the center of the occlusal surface. $1.0 \mathrm{~mm}$ shoulder finish line is made by the tip of tapered diamond stone which is equal to $1.0 \mathrm{~mm}$. Eight degree occlusal convergence is made by measuring tapering of diamond stone. Three millimeter occluso gingival height is made by reduction of the occlusal surface by diamond disc

\section{Machining fabrication technique}

For scanning the prepared tooth, a new restoration was created in the in-lab software version 3.88i (Sirona Dental Systems GmbH, 64625Bensheim, Germany). Restoration data was entered in the the window of the in-lab user interface.The designing of the crown shaped specimens the "Crown" was selected for "restoration" box, "Biogeneric", "Multilayer", or "Frame work" for the design technique box, and the mandibular second premolar was selected on the diagram of teeth selection

The prepared teeth in their blocks were then prepared by spraying them with a light reflecting antiglare spray "Cerec optispray" , and then fixed using plasticine on the shifting plate of the in-Lab scanner "inEos". 
The shifting plate with the blocks fixed on it was then positioned on the XY table of the inEos for taking the optical impression after adjusting the height of the scanner vertical unit with the rotary knob until the preparation was sharply focused. A top view scan was done of the preparation surface by clicking on the "acquire image", then the in-lab software uses those images for transforming them into a 3-D virtual models

After the milling process and prior to sintering, a low speed diamond bur was used to separate the completely milled restorations and to remove excess material at the site of connection with the ceramic block. Crowns are crystallized in IPS E-max oven (Furnace Programat p310), making crystallization and glazing cycle then try in Crown on the prepared toot.

\section{Pressing fabrication technique}

Making duplication to the e.max cad crown 10 times by dupliflexi duplicating material and used as reference (silicone index) for waxing procedures of pressed crowns to standardize the external surface of premolar. A wax pattern is manually built on each gypsum die to restore the anatomical features of the machined crowns using the sectioned silicone index as reference and $3 \mathrm{~mm}$ wax sprue is attached to the thickest point of the cusp. After pressing, recover crowns from the investment by airborne particle abrasion using 50 micro glass particles, remove the sprue and finishing then fit crown to the prepared tooth

\section{Cementation of the crowns}

All ceramic crowns are etched with 9\% hydrofluoric acid gel (Pentron clinical technologies, USA) for 60 seconds, rinsed with water and dried with air Group A of each Machinable and pressable ceramic crowns are cemented with total etch resin cement (cement it) The prepared teeth are etched with $37 \%$ phosphoric acid for 15 seconds then rinsed with water and dried with air then layer of bond is applied on the teeth and light polymerized for 15 seconds. A freshly mixed resin cement (cement it) is Applied on the fitting surface of each crown which is seated on the prepared tooth using static loading force $(10 \mathrm{~N})$, excess cement is removed with cotton pellet then the cement is light polymerized for 60 seconds on each side of the crown. Group B of each machinable and pressable ceramic crowns are cemented with self-adhesive resin cement (Rely-x 200) (3M ESPE Deutschland GmbH, Dental Products, Germany)

\section{Marginal fit evaluation}

Marginal fit is evaluated by measuring the gap between crown margin and finish line of the prepared tooth and is determined at eight specific locations, four locations at the middle of the four axial walls, mid-buccal, mesial, distal, and lingual as well as other four locations at the line angles between the axial walls. At every predetermined location, five readings were taken to give total of forty readings for each specimen. The mean of all readings was calculated from the mean values of cervical circumferential measuring locations. The mean of 40 values represented the mean marginal fit value for each crown. A specially designed device was machined from wood in order to aid in specimen holding during gap evaluation

Using costume made holding device all samples were positioned perpendicularly onto a digitalmicroscope, (Scope Capture Digital Microscope, Guangdong, China) and the images were captured and transferred to an IBM personal computer equipped with the Image-tool software (Image $\mathrm{J}$ 1.43U, National Institute of Health, USA magnification X 100)

\section{Sectioning technique}

The root portion of each crown is sectioned 3 $\mathrm{mm}$ below the cervical line and the coronal section is imbedded in chemically polymerized acrylic resin. Crowns are sectioned vertically in mesiodistal 


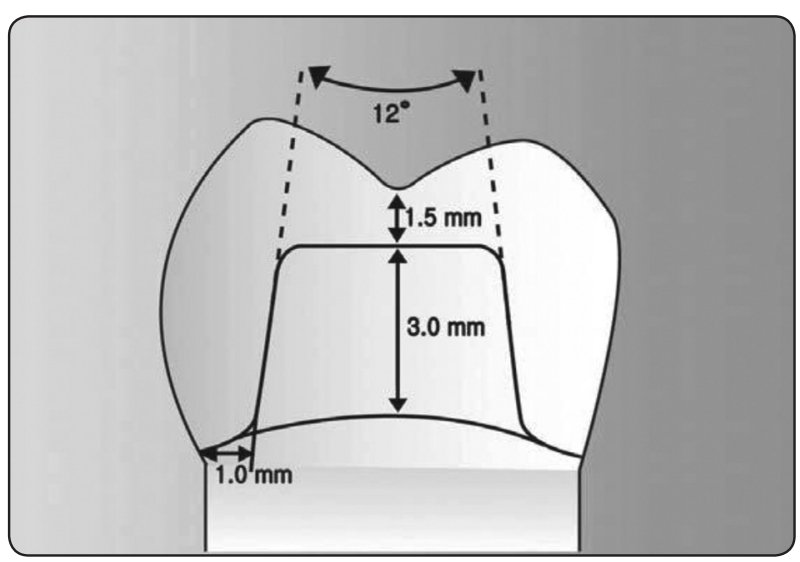

Fig. (3) The design of preparation

direction by using isoMet 4000 microsaw with cooling system (water) \& cool (anticorrosive agent) $30: 1$. Feeding rate $10 \mathrm{~mm}$ per minute and speed 2500 $\mathrm{rpm}$ according to the isoMet manual instructions and diamond disk 3 inch diameter and $0.5 \mathrm{~mm}$ thickness

\section{Internal adaptation evaluation}

Internal adaptation (also defined as cement film thickness) is measured as distance between the inner surface of the crown and the outer surface of the prepared tooth at three fixed locations.

Internal adaptation is measured by a digitalmicroscope, magnification X 100, and the images were captured and transferred to a IBM personal computer equipped with the Image-tool software Within the Image $\mathbf{J}$ software, all limits, sizes, frames and measured parameters are expressed in pixels. Therefore, system calibration was done to convert the pixels into absolute real world units. Calibration was made by comparing an object of known size (a ruler in this study) with a scale generated by the Image $J$ software. Then, the images of traced marginal path were overlaid and transferred to Image $\mathbf{J}$ software in order to calculate gap which measured in $(\mu)$

Data were presented as mean and standard deviation (SD) values. Regression model with repeated measures Analysis of Variance two ways (ANOVA) was used in testing significance for the effect of ceramic type and cement type.

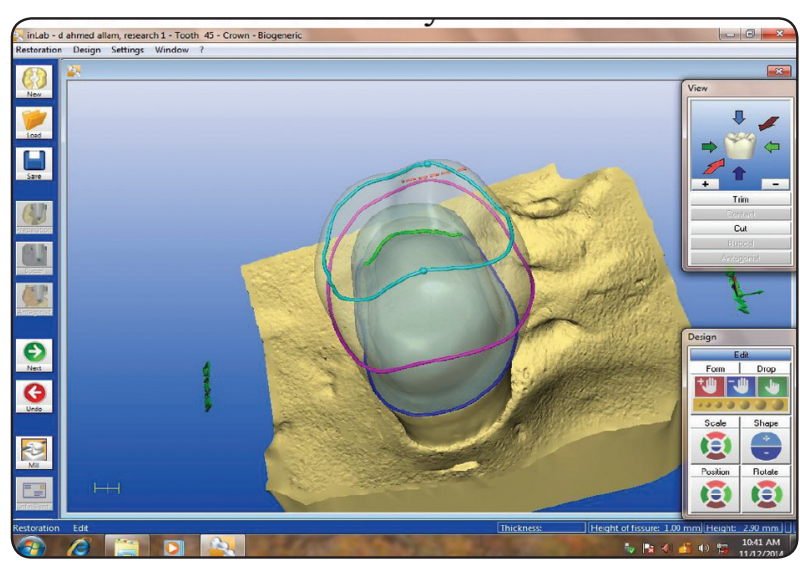

Fig. (4) Final "multilayer" crown shaped restoration design

\section{RESULTS}

Data analysis was performed in several steps. Initially, descriptive statistics for each group results. Two factorial analysis of variance ANOVA test of significance was used for comparing variables affecting gap mean values (ceramic and cement types) followed by pair-wise Tukey's post-hoc tests were performed to detect significance between subgroups. Statistical analysis was performed using Aasistat 7.6 statistics software for Windows (Campina Grande, Paraiba state, Brazil). P values $\leq 0.05$ are considered to be statistically significant in all tests.

\section{Vertical marginal gap}

The mean values and standard deviation of vertical marginal gap $(\mu \mathrm{m})$ as function of ceramic and cement types are summarized in table (2) and graphically drawn in figure (5).

\section{Effect of ceramic}

Regardless to cementation, totally it was found that press group recorded statistically significant $(\mathrm{P}<0.05)$ higher vertical marginal gap mean value $(55.07 \pm 1.1 \mu \mathrm{m})$ than CAD group $(49.99 \pm 5.57 \mu \mathrm{m})$ as indicated by two way ANOVA followed by pairwise Tukey's post-hoc tests 


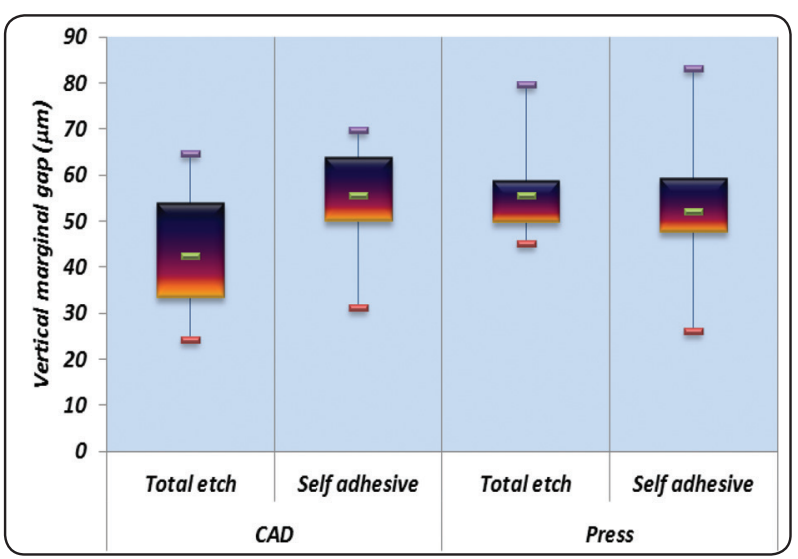

Fig. (5) Box plot of vertical marginal gap mean values as function of ceramic and cement types

\section{Effect of cement}

Regardless to ceramic, totally it was found that vertical marginal gap mean value of self-adhesive cement was statistically non-significant $(\mathrm{P}>0.05)$ higher $(54.77 \pm 0.8 \mu \mathrm{m})$ than total etch cement $(50.3 \pm 5.88 \mu \mathrm{m})$ as indicated by two way ANOVA followed by pair-wise Turkey's post-hoc tests.

\section{Internal gap}

The mean values and standard deviation of internal gap $(\mu \mathrm{m})$ as function of ceramic and cement types are summarized and graphically drawn in figure (6).

\section{Effect of ceramic}

Regardless to cementation, totally it was found that $\mathrm{CAD}$ group recorded statistically significant $(\mathrm{P}<0.05)$ higher internal gap mean value $(87.45$ $\pm 15.4 \mu \mathrm{m})$ than press group $(36.64 \pm 5.15 \mu \mathrm{m})$ as indicated by two way ANOVA followed by pairwise Tukey's post-hoc tests

\section{Effect of cement}

Regardless to ceramic, totally it was found that internal gap mean value of total etch cement was statistically significant $(\mathrm{P}<0.05)$ higher $(67.24 \pm$

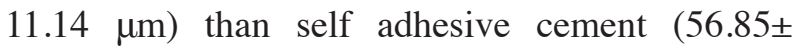
$9.4 \mu \mathrm{m})$ as indicated by two way ANOVA followed by pair-wise Tukey's post-hoc tests

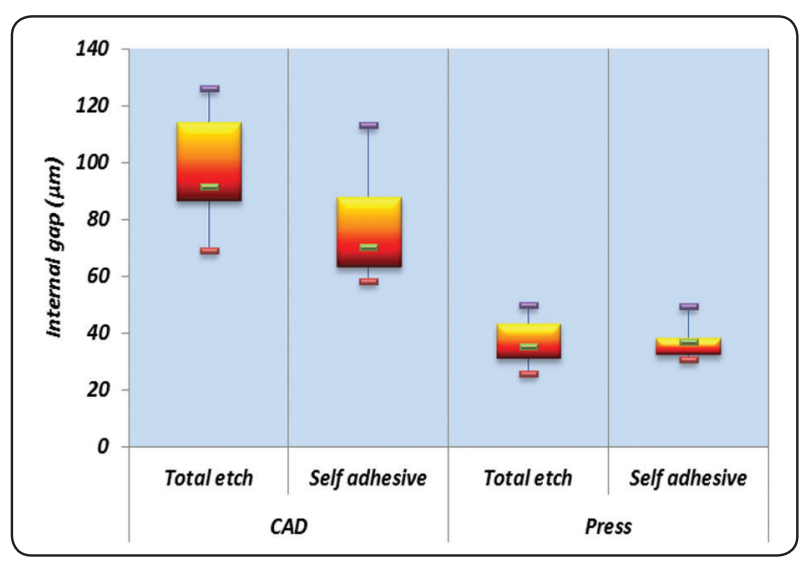

Fig. (6) Box plot of internal gap mean values as function of ceramic and cement types

\section{DISCUSSION}

Marginal fit, accuracy or adaptation is considered a key criterion used in the evaluation of fixed restorations and could be defined as a parameter that measures the distance between the margin of the restoration and the finish line of the prepared tooth whereas internal adaptation is defined as cement film thickness or the distance between internal surface of the crown and outer surface of the prepared tooth ${ }^{(44,45)}$.

High marginal accuracy and adequate internal adaptation are considered to be the major determining factor for successful clinical performance of a restoration ${ }^{(46-49)}$. Optimal marginal adaptation is an important factor in the biologic and mechanical stabilization of the fixed prosthesis. Increased marginal discrepancy causes maladjusted restorations and accumulation of bacterial plaque which results in a high risk of periodontal diseases and tooth decay ${ }^{(50,51)}$.

The hypothesis of this study, the method of construction of ceramic crowns and type of cementation will affect the marginal fit and internal adaptation of ceramic crowns was accepted.

Natural teeth were used in this study to simulate the clinical condition by providing microstructure 
to the luting cement that is nearly identical to the clinical situation. Standardized tooth preparation was done in this study to accurately control the variables of preparation dimensions ${ }^{(52)}$.

A paralleling device (Milling surveyor) was used to mount each tooth and to ensure the centralization and alignment of the tooth to the mold

The milling machine was used in teeth preparation to give more standardized preparation with the elimination of the human errors and mistakes as much as possible.

Recommended finish line types for optimal marginal adaptation are shoulder, shoulder-bevel and chamfer ${ }^{(45)}$. In this study a shoulder finish line was used.

It was previously found that adequate die spacing is an important factor for the accuracy of restoration margins ${ }^{(53)}$. To eliminate the effect of this factor on marginal discrepancy, all copings in this study were fabricated with a die spacer of $40 \mu$. In the CAD/CAM method die spacer $(40 \mu)$ is digitally adjusted. Whereas in pressing fabrication method, douple layer of die spacer material $40 \mu$ (Renfert) are applied on gypsum die of the prepared teeth and allowed to dry (where single layer of renfert die spacer material equal to 15-20 micro).

The Cerec in-Lab 3D was used in this study since its advanced software gives the system a wide range of indications. It gives chance for proper standardization since it allows the milling of frameworks, ${ }^{(54)}$ milling of veneer and framework for multilayer restoration, ${ }^{(55)}$ and also allows for fully contoured crowns and bridges out of solid blocks ${ }^{(54)}$.

In this study internal adaptation is measured by sectioning the crowns by IsoMet (microsaw) 4000 under water coolant. With those sections, it was easier to visualize the internal gap in each part of the tooth desired, and also direct measurement of internal gap was done.
In this study, marginal fit was evaluated by direct viewing with external measurements using a digital microscope at fixed magnification of $\mathrm{x} 100 .^{(56,57-58)}$ This measurement technique has the advantage of being noninvasive and is, therefore, useful to determine the precision of fit of the whole specimen margin.

However, it is difficult to repeat the measurements from an identical angle and to distinguish the real marginal gap from its projection. For this reason and for the purpose of measurements standardization, a specially designed holding device was used to hold the tested specimens under static load and to ensure the accuracy of seating of the samples on the prepared tooth. It also holds the tested specimens in place allowing the repeating of the measurements from an identical angle aligned with the focal plane of the microscope ${ }^{(59)}$.

In the present study, the marginal fit was evaluated for each crown specimen at eight specific locations, four locations at the middle of the four axial walls, mid-buccal, mesial, distal, and lingual as well as other four locations at the line angles between the axial walls. ${ }^{(60)}$ At every predetermined location, five readings were taken to give total of forty readings for each specimen. The mean of all readings was calculated from the mean values of cervical circumferential measuring locations. In order to avoid statistical variance as much as possible, all the measurements were performed by the same operator. ${ }^{(61)}$

The results of this study regardless of cementation, totally it was found that press group recorded statistically significant $(\mathrm{P}<0.05)$ higher vertical marginal gap mean value $(55.07 \pm 1.1 \mu \mathrm{m})$ than CAD group $(49.99 \pm 5.57 \mu \mathrm{m})$.

The results of the present study were in agreement with (Alireza et al. 2011) ${ }^{(62)}$ who stated that the marginal gap for the IPS empress restorations $(56 \mu)$ was significantly higher than that of ProCAD restorations $(36 \mu)$. 
On the other hand, these results were not in agreement with (S Reich et al) ${ }^{(63)}$ who stated that an overall gap width of $56 \mu$ was measured for IPS Empress, compared to the significantly increased value of $70 \mu$ for Cerec 3D,(Burcin et al 2012)(41) who stated that marginal discrepancies of IPS e.max CAD restorations were significantly greater when compared to IPS e.max press on enamel,but the difference was not statistically significant on dentin.

The explanation of these results could be attributed to the newly released version of the designing software (3D) has improved features related to automatic detection of the margins of the restorations. Compared to earlier versions, these new improvements are expected to improve final fit of the milled restorations. ${ }^{(64)}$ This proper marginal fit of CAD-CAM group might be due to recent advancements in respect to scanning technology (laser line scanner for digitizing the surface topography of the prepared tooth), ${ }^{(65)}$ software (the updating of the latest software provide precise detection of the preparation margin), and advanced milling strategy. ${ }^{(66)}$ However, from a clinical viewpoint, the statistically significant difference between the two systems is not relevant, since both systems still exhibit a clinically acceptable gap width of less than $100 \mu \mathrm{m}^{(63)}$.

The results of this study regardless to ceramic, totally it was found that vertical marginal gap mean value of self adhesive cement was statistically nonsignificant $(\mathrm{P}>0.05)$ higher $(54.77 \pm 0.8 \mu \mathrm{m})$ than total etch cement $(50.3 \pm 5.88 \mu \mathrm{m})$.

The explanation of this results could be attributed to the two ceramic materials have the same composition and silica content so, the effect of cement have similar effect.

The results of this study regardless to cementation, totally it was found that $\boldsymbol{C A D}$ group recorded statistically significant $(\mathrm{P}<0.05)$ higher internal gap mean value $(87.45 \pm 15.4 \mu \mathrm{m})$ than press group $(36.64 \pm 5.15 \mu \mathrm{m})$.
The explanation of these results could be attributed to application of two coats of die spacer material could facilitate easier seating of the crowns, maintain even cement film thickness, and reduce polymerization stresses. ${ }^{(67)}$ also when IPS e-max press ingot is pressed under 8500 by plunger into the mold,the ceramic flow through the mold leading to better internal adaptation. These ovens are equipped with a pneumatic press that activates an alumina plunger used to compress molten ceramic ingots. Press-on ceramics allow accurate reproduction of the anatomical features carved in the wax pattern and controlled processing of the ceramic material resulting in an accurate restoration with minimal internal structural defects ${ }^{(68)}$.

The results are in agreement with the results of the work performed by other investigators (Hisham A et al 2014) ${ }^{(42)}$ who stated that the heat-press group yielded the best internal crown adaptation results than the CAD-CAM group, (Burcin Akoglu et al 2012) ${ }^{(41)}$ who stated that the internal adaptation of IPS e.max press group at axial and occlusal surfaces is higher than the IPS e.max group and (Aboushelib et al 2012) $)^{(69)}$ who stated that pressable ceramic laminate veneers produced thinner cement film thickness compared to machinable ceramic veneers.

The results of this study regardless to ceramic, totally it was found that internal gap mean value of total etch cement was statistically significant $(\mathrm{P}<0.05)$ higher $(67.24 \pm 11.14 \mu \mathrm{m})$ than self-adhesive cement $(56.85 \pm 9.4 \mu \mathrm{m})$.

The explanation of these results could be attributed to the higher cement film thickness of total etch resin cement ( $25 \mu$ according to the manufacturer instructions) in compared to the thinner cement film thickness of self-adhesive resin cement (13 $\mu$ according to the manufacturer instructions), in addition to total etch resin cement is technique sensitive which requires multistep (etching, priming and bonding) in accordance to self-adhesive resin cement which requires one step where etch, primer and bond are incorporating in the cement. 
There are some limitations of this study. First, the difficulties in producing identical preparations may influence the accuracy of the results. Second, only one thickness of die spacer was evaluated for all the groups. Third, the results reported will not reflect the actual values in clinical situations because of different environmental and loading conditions.

The future recommendation in this study, it is recommended to further investigate the effect of aging with mechanical or thermal on the marginal fit of the restoration.

\section{CONCLUSIONS}

Within the limitation of this study, the following conclusions were drawn:

1. The CAD group recorded statistically significant high vertical marginal fit than press group.

2. The resin cement type has no effect on the marginal fit.

3. The press group recorded statistically significant high internal fit than CAD group.

\section{Clinical recommendation}

The e.max ceramic restorations can be made by pressing or CAD/CAM technique; both have comparable results within clinical acceptable limits.

Special acknowledgment to D. ahmad yossef, assistant lecturer of fixed prosthodontics for help in collecting samples and preparation and finishing the study.

\section{The author deny any conflicts of interest.}

\section{REFERENCES}

1. Shearer B, Gough MB, Setchell DJ. Influence of marginal configuration and porcelain addition on the fit of In-Ceram crowns. Biomater. 1996; 17(19):1891-5.

2. Layton D: A critical appraisal of the survival and complication rates of tooth-supported all-ceramic and metal-ceramic fixed dental prostheses: the application of evidencebased dentistry. Int J Prosthodont 2011;24:417-427
3. Syrek A, Reich G, Ranftl D, et al: Clinical evaluation of all-ceramic crowns fabricated from intraoral digital impressions based on the principle of active wavefront sampling. J Dent 2010;38:553-559

4. Land MF, Hopp CD: Survival rates of all-ceramic systems differ by clinical indication and fabrication method. J Evid Based Dent Pract 2010;10:37-38

5. Giannetopoulos S, van Noort R, Tsitrou E: Evaluation of the marginal integrity of ceramic copings with different marginal angles using two different CAD/CAM systems. J Dent 2010;38:980-986

6. Bindl A, M"ormann WH: Marginal and internal fit of allceramic CAD/CAM crown-copings on chamfer preparations. J Oral Rehabil 2005;32:441-447

7. Nakamura T, Dei N, Kojima T, et al: Marginal and Internal Fit of Cerec 3 CAD/CAM All-Ceramic Crowns. Int J Prosthodont 2003;16:244-247

8. Beier US, Kapferer I, Burtscher D, et al: Clinical performance of porcelain laminate veneers for up to 20 years. Int J Prosthodont 2012;25:79-85

9. M*ormann W, Wolf D, Ender A, et al: Effect of two selfadhesivecements on marginal adaptation and strength of esthetic ceramic CAD/CAM molar crowns. J Prosthodont 2009; 18:403 -410

10. Fasbinder DJ, Dennison JB, Heys D, Neiva G. A clinical evaluation of chairside lithium disilicate CAD/CAM crowns: a two-year report. J American Dent Associat (1939). 2010;141:10S-4S.

11. Liu P-R, Essig ME. Panorama of dental CAD/CAM restorative systems. Compendium of continuing education in dentistry (Jamesburg, NJ: 1995). 2008;29(8):482, 4, 6-8 passim.

12. Guess PC, Zavanelli RA, Silva N, Bonfante EA, Coelho PG, Thompson VP. Monolithic CAD/CAM lithium disilicate versus veneered Y-TZP crowns: comparison of failure modes and reliability after fatigue. Int J Prosthodont.2009;23(5):434-42.

13. Culp L, McLaren E. Lithium disilicate: the restorative material of multiple options. Compend Contin Educ Dent 2010;31(9):716-20

14. Giordano R, McLaren EA. Ceramics overview: classification by microstructure and processing methods. Compend Contin Educ Dent. 2010;31(9):682-4. 
15. Bindl A, Mörmann WH. Survival rate of mono-ceramic and ceramic-core $\mathrm{CAD} / \mathrm{CAM}$-generated anterior crowns over 2-5 years. Europ J oral scienc. 2004;112(2):197-204.

16. Kurbad A, Reichel K. Multicolored ceramic blocks as an esthetic solution for anterior restorations. Intern J Comp Dent. 2006;9(1):69-82.

17. El-Mowafy OM, Rubo MH. Influence of composite inlay/ onlay thickness on hardening of dual-cured resin cements. J Canda Dent Associat. 2000;66(3):147-51.

18. El-Mowafy O, Rubo M, El-Badrawy W. Hardening of new resin cements cured through a ceramic inlay. Operat Dent. 1998;24(1):38-44.

19. Ferracane JL. Correlation between hardness and degree of conversion during the setting reaction of unfilled dental restorative resins. Dent Mater. 1985;1(1):11-4.

20. Meng X, Yoshida K, Atsuta M. Influence of ceramic thickness on mechanical properties and polymer structure of dual-cured resin luting agents. Dent Mater. 2008; 24(5):594-9.

21. ASMUSSEN E. Restorative resins: hardness and strength vs. quantity of remaining double bonds. Europ J Oral Scienc. 1982;90(6):484-9.

22. Braga R, Ferracane J. Contraction stress related to degree of conversion and reaction kinetics. J Dent Resear. 2002;81(2):114-8.

23. Rasetto FH, Driscoll CF, Fraunhofer JA. Effect of light source and time on the polymerization of resin cement through ceramic veneers. J Prosthodont. 2001; 10(3):133-9.

24. Akgungor G, Akkayan B, Gaucher H. Influence of ceramic thickness and polymerization mode of a resin luting agent on early bond strength and durability with a lithium disilicate-based ceramic system. J Prosthet Dent. 2005;94(3):234-41.

25. Ceballos L, Garrido MA, Fuentes V, Rodríguez J. Mechanical characterization of resin cements used for luting fiber posts by nanoindentation. Dent Mater. 2007;23(1):100-5.

26. Hofmann N, Papsthart G, Hugo B, Klaiber B. Comparison of photo-activation versus chemical or dual-curing of resinbased luting cements regarding flexural strength, modulus and surface hardness. J Ora Rehab. 2001;28(11):1022-8.

27. Lu H, Mehmood A, Chow A, Powers JM. Influence of polymerization mode on flexural properties of esthetic resin luting agents. J Prosthet Dent. 2005;94(6):549-54.
28. Radovic I, Monticelli F, Goracci C, Vulicevic ZR, Ferrari M. Self-adhesive resin cements: a literature review. J Adhes Dent. 2008;10(4):251-8.

29. Braga R, Cesar P, Gonzaga C. Mechanical properties of resin cements with different activation modes. J Ora Rehab. 2002;29(3):257-62.

30. Jung H, Friedl K-H, Hiller K-A, Haller A, Schmalz G. Curing efficiency of different polymerization methods through ceramic restorations. Clinica ora investigat. 2001;5(3):156-61.

31. Kumbuloglu O, Lassila L, Vallittu PK. A study of the physical and chemical properties of four resin composite luting cements. Int J Prosthodont. 2003;17(3):357-63.

32. Ozyesil AG, Usumez A, Gunduz B. The efficiency of different light sources to polymerize composite beneath a simulated ceramic restoration. J Prosthet Dent. 2004;91(2):151-7.

33. Papazoglou E, Rahiotis C, Kakaboura A, Loukidis M. Curing efficiency of a photo-and dual-cured resin cement polymerized through 2 ceramics and a resin composite. Int $\mathrm{J}$ Prosthodont. 2005;19(1):34-6.

34. Rueggeberg F, Caughman W. The influence of light exposure on polymerization of dual-cure resin cements. Oper Dent. 1992;18(2):48-55.

35. Santos G, El-Mowafy O, Rubo JH, Santos M. Hardening of dual-cure resin cements and a resin composite restorative cured with QTH and LED curing units. J Canad Dent Associat. 2004;70(5):323-7.

36. Arrais CA, Giannini M, Rueggeberg FA. Kinetic analysis of monomer conversion in auto-and dual-polymerizing modes of commercial resin luting cements. J Prosthet Dent. 2009;101(2):128-36.

37. Moraes RR, Brandt WC, Naves LZ, Correr-Sobrinho L, Piva E. Light-and time-dependent polymerization of dualcured resin luting agent beneath ceramic. Acta Odontologica. 2008;66(5):257-61.

38. Arrais CA, Rueggeberg FA, Waller JL, de Goes MF, Giannini M. Effect of curing mode on the polymerization characteristics of dual-cured resin cement systems. J Dent. 2008;36(6):418-26.

39. Pazin MC, Moraes RR, Gonçalves LS, Borges GA, Sinhoreti MA, Correr-Sobrinho L. Effects of ceramic thickness and curing unit on light transmission through leucite-reinforced material and polymerization of dual-cured luting agent. J oral scien. 2008;50(2):131-6. 
40. Celik C, Gemalmaz D. Comparison of marginal integrity of ceramic and composite veneer restorations luted with two different resin agents: an in vitro study. Int J Prosthodont.2001;15(1):59-64.

41. Burcin A, Buket E, Coskun Y, Altay U, Yasemin K. Internal and marginal adaptation of pressable and computeraided design/computer-assisted manufacture onlay restorations. Int J Prosthodont. 2011; 25(3):262-4.

42. Hisham A, Matthew F, Roya Z, Hiroshi H. Marginal and internal adaptation of ceramic crown restorations fabricated with CAD/CAM technology and the heat-press technique. J Prosthet Dent. 2014; 112(2):249-56.

43. Aslı Akın, Suna Toksavul, \& Muhittin Toman. Clinical Marginal and Internal Adaptation of Maxillary Anterior Single All-Ceramic Crowns and 2-year Randomized Controlled Clinical Trial. Journal of Prosthodontics 24 (2015) 345-350 C _ 2014 by the American College of Prosthodontists.

44. Baig MR, Tan KB-C, Nicholls JI. Evaluation of the marginal fit of a zirconia ceramic computer-aided machined (CAM) crown system. J Prosthet Dent. 2010; 104(4):216-27.

45. Bindl A, Mörmann W. Marginal and internal fit of allceramic CAD/CAM crown-copings on chamfer preparations. J Ora Rehabilit. 2005;32(6):441-7.

46. Stappert CF, Chitmongkolsuk S, Silva NR, Att W, Strub JR. Effect of mouth-motion fatigue and thermal cycling on the marginal accuracy of partial coverage restorations made of various dental materials. Dent Mater. 2008;24(9):1248-57.

47. Krifka S, Anthofer T, Fritzsch M, Hiller K, Schmalz G, Federlin M. Ceramic inlays and partial ceramic crowns: influence of remaining cusp wall thickness on the marginal integrity and enamel crack formation in vitro. Oper Dent. 2009;34(1):32-42.

48. Giannetopoulos S, Van Noort R, Tsitrou E. Evaluation of the marginal integrity of ceramic copings with different marginal angles using two different CAD/CAM systems. J Dent. 2010;38(12):980-6.

49. Addi S, Hedayati-Khams A, Poya A, Sjögren G. Interface gap size of manually and CAD/CAM-manufactured ceramic inlays/onlays in vitro. J Dent. 2002;30(1):53-8.

50. Albert F, El-Mowafy O. Marginal adaptation and microleakage of Procera AllCeram crowns with four cements. J Prosthet Dent. 2005;93(4):394.
51. Sorensen JA, Strutz JM, Avera SP, Materdomini D. Marginal fidelity and microleakage of porcelain veneers made by two techniques. J Prosthet Dent. 1992;67(1):16-22.

52. Beschnidt S, Strub J. Evaluation of the marginal accuracy of different all-ceramic crown systems after simulation in the artificial mouth. J Oral Rehabilit. 1999;26(7):582-93.

53. Gonzalo E, Suárez MJ, Serrano B, Lozano JF. A comparison of the marginal vertical discrepancies of zirconium and metal ceramic posterior fixed dental prostheses before and after cementation. J Prosthet Dent. 2009;102(6):378-84.

54. Filser F, Kocher P, Weibel F, Lüthy H, Schärer P, Gauckler L. Reliability and strength of all-ceramic dental restorations fabricated by direct ceramic machining (DCM). Internat J Comp Dent. 2001;4(2):89-106.

55. Schmitter M, Mueller D, Rues S. Chipping behaviour of all-ceramic crowns with zirconia framework and CAD/ CAM manufactured veneer. J Dent. 2012;40(2):154-62.

56. Sulaiman F, Chai J, Jameson LM, Wozniak WT. A comparison of the marginal fit of In-Ceram, IPS Empress, and Procera crowns. Int J Prosthodont. 1996;10(5):478-84.

57. Pak H-S, Han J-S, Lee J-B, Kim S-H, Yang J-H. Influence of porcelain veneering on the marginal fit of Digident and Lava CAD/CAM zirconia ceramic crowns. J Advanc prosthodont. 2010;2(2):33-8.

58. Trifkovic B, Budak I, Todorovic A, Hodolic J, Puskar T, Jevremovic D, et al. Application of replica technique and SEM in accuracy measurement of ceramic crowns. Measurement Science Review. 2012;12(3):90-7.

59. Chan C, Haraszthy G, Geis-Gerstorfer J, Weber H, Huettemann H. Scanning electron microscopic studies of the marginal fit of three esthetic crowns. Quintessence international (Berlin, Germany: 1985). 1989;20(3):189.

60. Hamza TA, Ezzat HA, El-Hossary MMK, Katamish HAEM, Shokry TE, Rosenstiel SF. Accuracy of ceramic restorations made with two CAD/CAM systems. J prosthet Dent. 2013;109(2):83-7.

61. Gonzalo E, Suarez MJ, Serrano B, Lozano J. Comparative analysis of two measurement methods for marginal fit in metal-ceramic and zirconia posterior FPDs. Int J Prosthodont. 2008;22(4):374-7.

62. Alireza K, Tabassom H, Farokh A, Foroogh K, Mohammed A, Richard V. Marginal Gap, Internal Fit, and Fracture Load of Leucite-Reinforced Ceramic Inlays Fabricated by CEREC inLab and Hot-Pressed Techniques. J Prosthodont. 2011;20(7):535-40. 
63. Reich S, Gozdowski S, Trentzsch L, Frankenberger R, Lohbauer U. Marginal Fit of Heat-pressed vs CAD/CAM Processed All-ceramic Onlays Using a Milling Unit Prototype. Oper Dent. 2008; 33(6):644-50.

64. White S, Suh P, Yu Z, Johnson R. Effect of fit adjustment on CEREC CAD-CAM veneers. Ameri J Dent. 1997;10(1):46-51.

65. Beuer F, Naumann M, Gernet W, Sorensen JA. Precision of fit: zirconia three-unit fixed dental prostheses. Clinic Ora Investigat. 2009;13(3):343-9.

66. Mörmann WH, Bindl A. The Cerec 3--a quantum leap for computer-aided restorations: initial clinical results.
Quintessence international (Berlin, Germany: 1985). 1999;31(10):699-712.

67. Cho S-H, Chang W-G, Lim B-S, Lee Y-K. Effect of die spacer thickness on shear bond strength of porcelain laminate veneers. The J Prosthet Denty. 2006; 95(3):201-8.

68. Shuman I. Aesthetic treatment with a pressed ceramic veneer material: case reports. Dentistry today. 2004; 23(11):80, 2, 4 passim-, 2, 4 passim.

69. Aboushelib MN, Elmahy WA, Ghazy MH. Internal adaptation, marginal accuracy and microleakage of a pressable versus a machinable ceramic laminate veneers. J Dent. 2012;40(8):670-7. 